\title{
Residential mobility among foreign-born
living in Sweden is associated with lower mortality
}

\author{
This article was published in the following Dove Press journal: \\ Clinical Epidemiology \\ I July 2010 \\ Number of times this article has been viewed
}

\begin{abstract}
There have been few longitudinal studies on the effect of within-country mobility on patterns of mortality in deceased foreign-born individuals. The results have varied; some studies have found that individuals who move around within the same country have better health status than those who do not change their place of residence. Other studies have shown that changing one's place of residence leads to more self-reported health problems and diseases. Our aim was to analyze the pattern of mortality in deceased foreign-born persons living in Sweden during the years 1970-1999 in relation to distance mobility. Data from Statistics Sweden and the National Board of Health and Welfare was used, and the study population consisted of 281,412 foreign-born persons aged 16 years and over who were registered as living in Sweden in 1970. Distance mobility did not have a negative effect on health. Total mortality was lower (OR 0.71; 95\% CI 0.69-0.73) in foreign-born persons in Sweden who had changed their county of residence during the period 1970-1990. Higher death rates were observed, after adjustment for age, in three ICD diagnosis groups "Injury and poisoning", "External causes of injury and poisoning", and "Diseases of the digestive system" among persons who had changed county of residence.
\end{abstract}

Keywords: residential mobility, health, foreign-born, immigrant, Sweden, mortality

\section{Residential mobility in foreign-born persons living in Sweden is associated with lower mortality}

Earlier studies have shown a relationship between residential mobility and health. The results of these studies have varied; some studies have found that people who move their place of residence have better health status than those who have not. ${ }^{1,2}$ In such studies, health was measured by using registrations of death or chronic illness $^{1}$ or risk of mothers having adverse birth outcome. ${ }^{2}$ Other studies have shown that changing one's place of residence tends to lead to more self-reported health problems. $^{3-5}$ In several studies, psychiatric health problems such as schizophrenia and depression have been shown to be associated with residential mobility. ${ }^{6-8}$ According to some studies, residential mobility can explain differences in mortality rate between different areas or districts. ${ }^{9,10}$ To our knowledge, the relationship between cause of death in foreign-born individuals and residential mobility has not been studied previously.

Today, migration is a ubiquitous process and issue that affects nearly every country of the world. ${ }^{11}$ In 2005, the total number of migrants globally was 200 million, with the highest number (56.1 million) living in Europe. ${ }^{12}$ People are not only migrating but also changing their place of residence within the same coun-
Correspondence: Björn Albin

School of Health and Caring Sciences, Linnaeus University, SE-35I 95 Växjö, Sweden

Tel +46 $470708304 ;+46708673794$

$\mathrm{Fax}+4647036310$

Email bjorn.albin@vxu.se 
try. Almost $20 \%$ of the population of USA changes their place of residence each year, and within countries such as USA, Australia, Canada, United Kingdom, and Japan, the 5-year mobility rate ranges from $36 \%$ to $48 \% .{ }^{13}$ Residential mobility is an issue in Sweden also, and it has an effect on society by influencing and being affected by the labour market, education, social services, and economic development, for example. During the past few decades, a large proportion of the population has moved within Sweden, especially from rural to urban areas and from the north to the south of Sweden. ${ }^{14-16}$ During the 1990 s, due to persons changing place of residence, the populations of all counties in Sweden have decreased - with the exception of the three largest urban areas of Stockholm, Gothenburg, and Malmö, and also the counties of Halland and Uppsala. ${ }^{15}$

At present, there are just over 1 million foreign-born individuals living in Sweden, which is equivalent to $12.4 \%$ of the total Swedish population. ${ }^{16}$ The immigrant population is dominated by labor migrants from the Nordic countries, especially Finland, and European countries such as former Yugoslavia, Germany, and Poland, but the whole migrant population represents about 140 different nationalities. ${ }^{16}$ In previous longitudinal studies of 723,948 foreign-born and native-born Swedes during 1970-1999, increased mortality and dissimilarities in mortality patterns were found, and migration was shown to have an influence on health. ${ }^{17,18}$ As far as we know, there have been no national or international longitudinal studies examining causes of death among foreign-born persons in relation to whether or not they have changed their place of residence.

The aim of this study was to analyze the pattern of mortality and in main death diagnosis according to International Classification of Diseases (ICD) classification in deceased foreign-born persons living in Sweden during the years 1970-1999, specifically in relation to their distance mobility - such as change(s) of county of residence. We tested the null hypothesis that there would be no differences in mortality as a result of residential mobility.

\section{Material and methods}

The study population consisted of 281,412 foreign-born individuals aged 16 years and over who were registered as living in Sweden in 1970, and who had taken part in the five national censuses of 1970, 1975, 1980, 1985, and 1990. The original database has been described previously, ${ }^{17}$ and it was set up by CAFO (the Centre for Labour Market Research) at Växjö University. The data came from Statistics Sweden (SCB) and the National Board of Health and Welfare Centre for Epidemiology, covering the period 1970-1999 and including all 361,974 foreign-born persons registered as living in Sweden in 1970. These data relate to the situation on November 1, 1970 and were taken from the national census of 1970, which was a total census, and checked against the National Population Register (RTB), which included data up to December 31, 1999.

Exclusion criteria were: (1) if no information was available, (2) if a person had emigrated from Sweden, or (3) if a person had not taken part in all five national censuses from 1970-1990. Thus, 80,562 (22.3\%) foreign-born persons in total were excluded from the database. In the excluded group, 41,885 individuals (52.0\%) were men and 38,677 (48.0\%) were women, and the mean age was 51.4 years for men and 59.1 years for women. The study population thus consisted of 281,412 foreign-born persons after the exclusion criteria had been applied.

The analysis first involved a comparison of mortality in foreign-born persons who had not changed county of residence, in relation to sex, country/region of birth, and occupation with those who had not changed county of residence. An analysis was also done concerning the pattern in relation to gender. Individuals from the following countries in particular were studied: Denmark, Finland, Norway, Iceland, former Yugoslavia, Poland, and Germany. Other European countries and non-European countries were also considered. The rationale for studying the countries selected was that increased mortality and different patterns of cause of death had been shown in these migrant groups in previous studies, ${ }^{17,18}$ and that they constituted the predominant groups (74.9\%) of all migrants in Sweden included in the database during the period studied.

\section{Statistical analysis}

Values are given as numbers, means, and percentages. Mortality risks were calculated as odds ratios (OR) with $95 \%$ confidence interval (CI). The OR was calculated for both the group that changed county of residence and the group that did not change county of residence by using the other as a reference. Comparisons were done with tests of significance using the Chi-square test. A value of $P<0.05$ was considered statistically significant. ${ }^{19}$ The importance of change of residence, adjusted for age, sex, and marital status, for the dependent variable death 
was tested with multiple logistic regression analysis. All analyses were performed using SPSS software (version 12.0.2; SPSS Inc., chicago, IL).

\section{Ethics}

The ethics committee of the University of Lund approved the study after all other Swedish university ethics committees had reviewed it.

\section{Results}

\section{Mortality}

During the time period 1970-1990, 227,040 foreign-born individuals (99,767 men and 127,273 women) had lived in the same county, and 54,372 foreign-born individuals $(27,050$ men and 27,322 women) had changed their county of residence (see Table 1). More men than women had changed their place of residence during 1970-1990: $21.3 \%$ as opposed to $17.7 \%$, respectively.

Mean age in 1970 was significantly lower for those who had changed their place of residence, in total 5.9 years (mean age 31.9 vs 37.8 years). The corresponding values when men and women were analyzed separately were 5.1 years for men (mean age 36.6 vs 31.4 years), and 6.3 years for women (mean age 38.9 vs 32.6 years).
Table 1 shows that there was a significantly higher relative risk of death in those who had not changed their place of residence during the time period 1970-1990; OR was 1,051 for men who had not changed their place of residence, as opposed to 0.73 for men who had, and the corresponding figures were 1.06 and 0.654 for women. Irrespective of country of birth, the relative risk of death was higher in those who did not change their county of residence, except for those from former Yugoslavia and persons who were stateless or who had unknown county/region of birth (see Table 1). The percentage of individuals living alone was significantly higher in those who changed their county of residence (44.2\% as opposed to $41.1 \%$ ).

The breakdown of occupations is only analyzed in men, and showed a similar pattern in the men who had changed their place of residence and in those who had not, with 3 exceptions: those with "bookkeeping and clerical work", "armed forces", and those engaged in "production work" (see Table 2). Data for women are not given here since the proportion with "no occupation" was high irrespective of whether or not they had changed their county of residence: $52.5 \%$ and $51.3 \%$, respectively.

Table I Description of living and deceased foreign-born persons living in Sweden included in the 5 national censuses studied

\begin{tabular}{|c|c|c|c|c|c|c|}
\hline \multirow[t]{2}{*}{ Variables } & \multicolumn{3}{|c|}{ Changed county of residence during $1970-1990$} & \multicolumn{3}{|c|}{ Did not change county of residence during $1970-1990$} \\
\hline & Total & $\begin{array}{l}\text { Deceased } \\
(\%)\end{array}$ & $\begin{array}{l}\text { Odds ratio } \\
(95 \% \mathrm{Cl})\end{array}$ & Total & $\begin{array}{l}\text { Deceased } \\
\text { (\%) }\end{array}$ & $\begin{array}{l}\text { Odds ratio } \\
(95 \% \mathrm{Cl})\end{array}$ \\
\hline \multicolumn{7}{|l|}{ Gender } \\
\hline Men (\%) & $27,050(21.3)$ & $3,324(12.3)$ & $0.72(0.69,0.74)$ & $99,767(78.7)$ & $|8,02|(|8|)$. & $1.05(1.05,1.06)$ \\
\hline Women (\%) & $27,322(17.7)$ & $2,601(9.5)$ & $0.65(0.63,0.68)$ & $127,273(82.3)$ & $19,240(15.1)$ & $1.05(1.04,1.05)$ \\
\hline \multicolumn{7}{|l|}{$\operatorname{Age}^{a}(95 \% \mathrm{Cl})$} \\
\hline Men & $31.4(3|.2,3| .5)$ & $42.2(41.8,42.6)$ & 1.12 & $36.5(36.4,36.5)$ & 47.I $(47.0,47.3)$ & 1.12 \\
\hline Women & $32.6(32.4,32.7)$ & $48.1(47.6,48.6)$ & 1.12 & $38.9(38.8,39.0)$ & $52.8(52.6,52.9)$ & 1.13 \\
\hline \multicolumn{7}{|l|}{ Country of birth (\%) } \\
\hline \multicolumn{7}{|l|}{ European countries } \\
\hline Denmark & $4,051(7.5)$ & $583(9.8)$ & $0,75(0,69,0.82)$ & $18,486(8.1)$ & $3,729(10.0)$ & $1.05(1.04,1.07)$ \\
\hline Finland & $25,370(46.7)$ & $2,443(4 \mid .2)$ & $0.78(0.75,0.8 \mathrm{I})$ & 92,779 (40.9) & $12,168(32.7)$ & $1.06(1.05,1.07)$ \\
\hline Norway/lceland & $4,036(7.4)$ & $623(10.5)$ & $0.74(0.68,0.80)$ & $21,600(9.5)$ & $4,76 \mid(\mid 2.8)$ & $1.05(1.04,1.06)$ \\
\hline Yugoslavia & $3,926(7.2)$ & $313(5.3)$ & $0.96(0.87,1.07)$ & $13,446(5.9)$ & $\mathrm{I}, 127(3.0)$ & I.0I $(0.98,1.04)$ \\
\hline Poland & $\mathrm{I}, 173(2.2)$ & $158(2.7)$ & $0.65(0.56,0.76)$ & $5,611(2.5)$ & $\mathrm{I}, 248(3.3)$ & $1.07(1.05,1.10)$ \\
\hline Germany & $4,504(8.3)$ & 470 (7.9) & $0.70(0.64,0.77)$ & $21,855(9.6)$ & $3,439(9.2)$ & $1.06(1.05,1.08)$ \\
\hline $\begin{array}{l}\text { Another European } \\
\text { country }\end{array}$ & $8,178(15.0)$ & $900(15.2)$ & $0.63(0.59,0.67)$ & $38,634(17.0)$ & 7,349 (19.7) & $1.08(1.07,1.09)$ \\
\hline Non-European & $3,092(5.7)$ & $425(7.2)$ & $0.63(0.58,0.70)$ & $14,397(6.3)$ & $3,376(9.1)$ & $1.08(1.07,1.09)$ \\
\hline Stateless/unknown & $42(0.1)$ & $10(0.2)$ & $0.82(0.43,1.55)$ & $212(0.1)$ & $64(0.2)$ & $1.04(0.93,1.15)$ \\
\hline \multicolumn{7}{|l|}{ Marital status ${ }^{\mathrm{b}}$} \\
\hline Married/co-habiting & $30,350(55.8)$ & $2,44 I(4 I . I)$ & & $133,722(58.9)$ & $16,168(43.4)$ & \\
\hline Living alone & $24,022(44.2)$ & $3,484(58.8)$ & $0.69(0.66,0.72)$ & 93,318 (4I.I) & $21,093(56.6)$ & $1.04(1.03,1.04)$ \\
\hline
\end{tabular}

Notes: aMean age in 1970; 'Data from the national census of 1990. 
Table 2 Deceased foreign-born men living in Sweden who were included in 5 national censuses, in relation to occupation based on the nordic standard classification of occupations (NYK) 1965

\begin{tabular}{|c|c|c|c|}
\hline \multirow[t]{2}{*}{ Occupations in 1970} & \multirow{2}{*}{$\frac{\text { Changed county of residence }}{\text { Men (\%) }}$} & \multirow{2}{*}{$\frac{\text { Did not change county of residence }}{\text { Men (\%) }}$} & \multirow[t]{2}{*}{$P$-value } \\
\hline & & & \\
\hline Professional, technical and related work & $456(13.7)$ & $2,456(13.6)$ & 0.876 \\
\hline Administrative and managerial work & $71(2.1)$ & $399(2.2)$ & 0.781 \\
\hline Book-keeping and clerical work & $57(1.7)$ & $505(2.8)$ & $<0.001$ \\
\hline Sales work & $126(3.8)$ & $782(4.3)$ & 0.166 \\
\hline Agricultural, forestry and fishing work & $13 \mid(3.9)$ & $697(3.9)$ & 0.849 \\
\hline Mining and quarrying work & $28(0.9)$ & $124(0.7)$ & 0.336 \\
\hline Transport and communications work & $123(3.8)$ & $738(4.1)$ & 0.305 \\
\hline Production work ${ }^{\mathrm{a}}$ & $1,106(33.3)$ & $6,405(35.5)$ & 0.078 \\
\hline Production work ${ }^{\mathrm{b}}$ & $419(12.4)$ & $2,583(\mid 4.3)$ & 0.021 \\
\hline Service work & $126(3.9)$ & $794(4.4)$ & 0.123 \\
\hline Armed forces & $9(0.3)$ & $16(0.1)$ & 0.005 \\
\hline $\begin{array}{l}\text { Workers reporting occupations that were } \\
\text { unidentifiable or inadequately described }\end{array}$ & II (0.3) & $43(0.2)$ & 0.332 \\
\hline No occupation registered & $661(19.9)$ & $2,479(\mid 3.8)$ & $<0.001$ \\
\hline Total & 3,324 & $|8,02|$ & \\
\hline
\end{tabular}

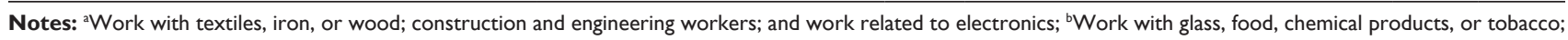
longshoremen and warehousemen; and all other production work.

The influence of change of residence was related to a lower mortality, adjusted for age, sex, and marital status, in a logistic regression model $(\mathrm{OR}=0.93)$ (see Table 3).

\section{Causes of death}

Table 4 shows crude differences in cause of death, with higher death rates in males who had changed their county of residence in 5 ICD diagnosis groups. The incidence of death in the groups "Injury and poisoning" and "External causes of injury and poisoning" was 5.8\% vs $3.5 \%$ and $2.6 \%$ vs $1.5 \%$, and remained significant even after adjusting for age (data not shown; $P=0.003$ and $P=0.049$, respectively). In women, crude differences in causes of death were found in 4 ICD groups. After adjustment for age, women who had changed their county of residence had significantly higher proportions in the ICD diagnosis groups "Diseases of the digestive system" and "Injury and poisoning" than women who had not changed their county of residence: $4.1 \%$ vs $3.3 \%$ and $3.8 \%$ vs $2.3 \%$ (data not shown; $P=0.006$ and $P=0.002$, respectively).

\section{Discussion}

As a longitudinal study on the pattern of mortality in deceased foreign-born individuals in relation to distance mobility, such as change of county residence, this study is unique. The main finding of the study was a lower mortality in foreign-born persons in Sweden who had changed their county of residence, indicating that distance mobility (change of county of residence) did not have a negative effect on health. This finding was also confirmed in the multiple regression model with change of place of residence, adjusted for age, as a significantly influential factor related to lower mortality.

One interpretation of the results would be that those who changed their county of residence might have been a selection of individuals with better health status, as found in earlier studies. ${ }^{1,2}$

The importance of strong social networks in relation to good health has been shown in several earlier studies. ${ }^{20-22}$ People who have changed their county of residence most probably affect their own social networks negatively, and have difficulty in maintaining the networks that existed before they moved. For

Table 3 Multiple regression with change of residence adjusted for age, sex, and marital status in relation to death

\begin{tabular}{lllll}
\hline Dependent variable & Independent variable & B-value & Significance & Odds ratio (95\% Cl) \\
\hline Death & Age & 0.117 & $<0.00 \mathrm{I}$ & $1.13(\mathrm{I} .12, \mathrm{I} .13)$ \\
& Sex (female/male) & 0.782 & $<0.00 \mathrm{I}$ & $2.19(2.13,2.24)$ \\
& $\begin{array}{l}\text { Marital status (married, } \\
\text { cohabiting, or living alone) } \\
\text { Change of residence (no/yes) }\end{array}$ & -0.520 & $<0.00 \mathrm{I}$ & $0.60(0.58,0.61)$ \\
& & -0.073 & $<0.00 \mathrm{I}$ & $0.93(0.90,0.96)$ \\
\hline
\end{tabular}




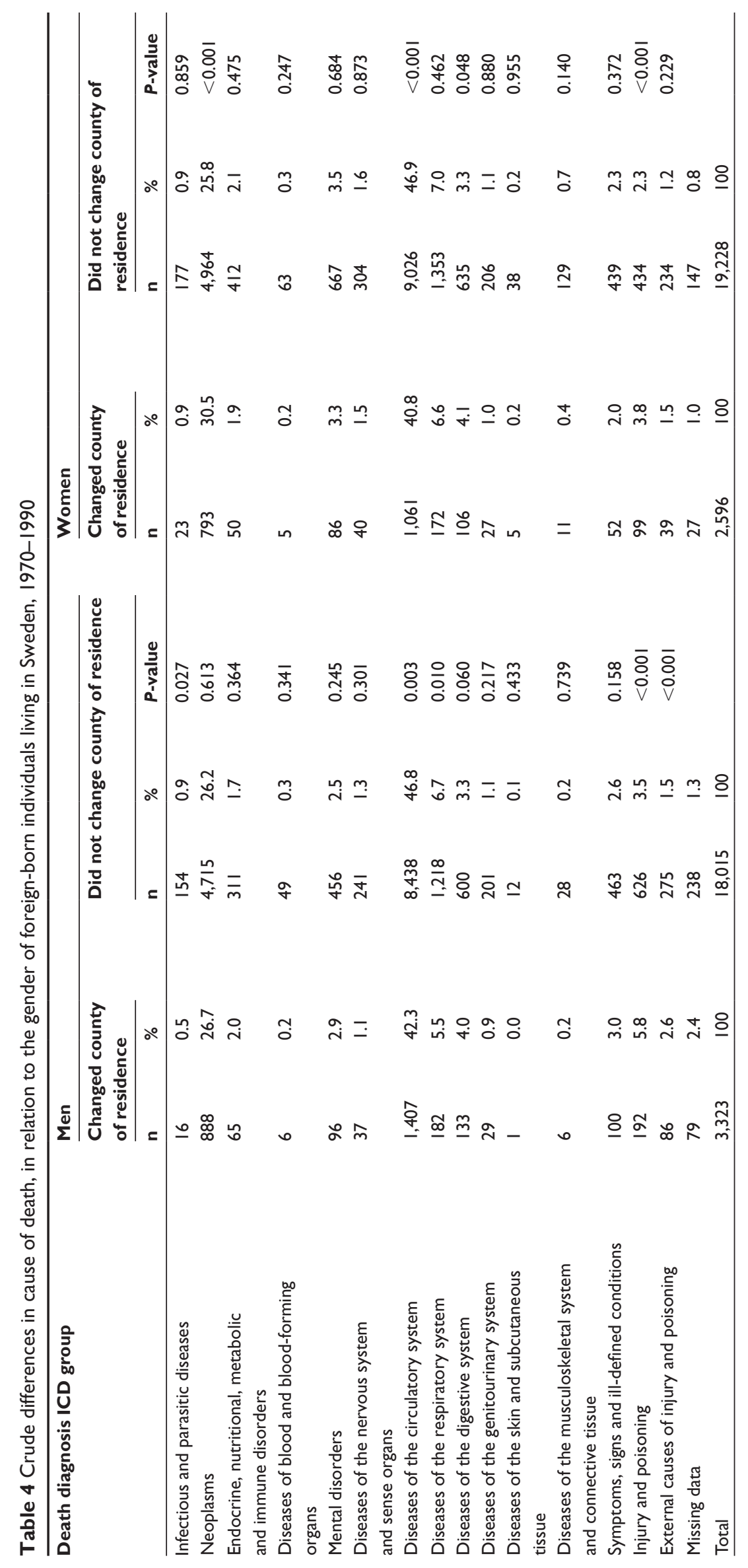


several years, the Swedish immigration policy was to try to spread out the places of residence of foreign-born people all over Sweden, and to try to avoid concentration of immigrant groups in any particular area. ${ }^{23}$ One explanation of the findings in this study, especially lower mortality in those who had changed their county of residence, could be the rationale to move. One reason might be to move to an area with people from the same country or region of birth, thereby increasing the possibility of a better social network, which could in turn improve their health.

It is important to notice that during the study period, people could have moved out of a county and then back again between the census assessments, even though this was not registered in the database. People could also have changed their place of residence within the one county, such as moving from a rural area to an urban environment. Short distance mobility and a short-lived change of residence are not likely to affect social networks as much as long distance mobility. ${ }^{24}$

Male occupation was not shown to be an explanatory factor regarding the differences in mortality between those who had changed their county of residence and those who had not; the distribution of occupations differed for less than $20 \%$ of the total number of deceased persons.

There were a higher proportion of men in production work in those that had not changed county of residence, and it cannot be excluded that there are an overrepresentation of injuries and poisoning in this group possibly related to work-related injuries. The difference concerning armed forces is not possible to evaluate since the group is very limited in numbers ( 9 vs $16,0.3 \%$ vs $0.1 \%$ ).

Not having an occupation could be of importance in terms of being one reason to change one's place of residence; a larger proportion of men with no occupation registered was found in the group that had changed their county of residence (19.9\% vs $13.8 \%)$. For women, it was impossible to evaluate the influence of occupation on mortality since more than half of the women who $\mathrm{had} / \mathrm{had}$ not changed their county of residence $(52.5 \%$ and $51.3 \%$, respectively) were registered as having no occupation. The main reason for this large proportion could be that many women were not gainfully employed, but worked at home as housewives. ${ }^{25} \mathrm{~A}$ higher rate of unemployment in women, or more part-time work among women than men $^{26}$ would also help to explain the large proportion.

To a large extent, the analysis of cause of death showed a similar pattern between those who had and had not changed their county of residence. In this study, we found no reason to believe that people who changed their county of residence did this because of a specific disease. Some earlier studies have found a relationship between mental illness and residential mobility. ${ }^{6-8}$ The finding in this study of significantly higher percentages deceased in ICD diagnosis group "External causes of injury and poisoning" in men who had changed their county of residence, may be an indication of greater vulnerability to mental health problems and should be investigated further. The ICD diagnosis group includes sub-diagnoses such as self-destructive behavior and suicide.

After adjustment for age, higher death rates were found in people who had changed their county of residence and who belonged to ICD diagnosis groups relating to more acute conditions. Both men and women who had changed their county of residence had significantly higher percentages of deceased in the ICD diagnosis group "Injury and poisoning". Within this ICD diagnosis group, the sub-diagnoses relate to accidents of different kinds, and the findings may indicate a greater risk of having an accident if one changes one's place of residence. A new physical and work environment and a lack of knowledge and safety training can increase the risk of having an accident. ${ }^{27,28}$ Women who had changed their county of residence showed a higher death rate in the ICD diagnosis group "Diseases of the digestive system", but this did not remain concerning "Neoplasms" after age-adjustment. There was no apparent explanation for this, and it could be a random finding without any implication.

\section{Strengths and limitations}

This study was based on data from Statistics Sweden and from the National Board of Health and Welfare Centre for Epidemiology. Causes of death were registered according to the system of International Classification of Diseases (ICD) revision 9 (1997) or 10 (1998) with the same structure of classification between the main groups of diagnosis.

The data used to establish the database came from the Population and Housing Census of 1970, which is considered to be a total census - as it was compulsory by law to take part 
in it. No number of dropouts has been estimated for the total census, only for some of the variables such as "occupation", and Statistics Sweden estimated the dropout rate for this variable to be $3.5 \%-4.5 \%$. It can only be speculated whether or not participation in the census was related to health problems and whether there were a number of migrants who did not take part in it. Another reason for migrants not participating in the census would be language problems.

In total, 80,562 (22.3\%) foreign-born persons were excluded from the database because they had emigrated from Sweden or had not taken part in all 5 national censuses from 1970 to 1990. The "excluded" group had a higher proportion of men than the group studied $(54.9 \%$ and $45.1 \%$, respectively) and a higher mean age for both men and women ( 51.4 years vs 35.4 years and 59.1 years vs 37.8 years, respectively). A consequence with the study design (participants taking part in 5 national censuses) might be a survival bias due to attrition. It can only be speculated whether diseased subjects were more prone to not change county of residence.

The finding of a large proportion of women registered as having no occupation was due to the way in which the questionnaire used in the national census had been constructed with no classification of occupation for those being part-time employed ( $<20$ hours/week) or being house-wives (National Bureau of Statistics, 1973). This limits the results as concerns women, but since only $47.5 \%$ vs $48.5 \%$ had an occupation registered, it was not fruitful to analyze further. The interpretation is then limited to men in respect to occupation. The possible influence of confounding an effect of occupation of change of county of residence cannot be excluded.

Part-time work with less than 20 hours per week and domestic work were not registered. In Sweden, the corresponding percentage of gainfully employed persons was $42.3 \%$ in men and $35.0 \%$ in women during the same period.

This study has shown that distance mobility (changing one's county of residence) did not have a negative effect on health. A lower mortality was found in foreign-born individuals in Sweden who had changed their county of residence during the period 1970-1990. After adjustment for age, higher death rates were found in those who had changed their county of residence, in 4 ICD diagnosis groups that described more acute conditions such as "Injury and poisoning" and "External causes of injury and poisoning".

\section{Acknowledgments}

This work was supported by grants from the research profile AMER (labor market, migration, and ethnic relations), Växjö University, Sweden, and the Faculty of Humanities and Social Sciences, Växjö University.

\section{Disclosure}

The authors report no conflicts of interest in this work.

\section{References}

1. Norman P, Boyle P, Rees P. Selective migration, health and deprivation: a longitudinal analysis. Soc Sci Med. 2005;60:2755-2771.

2. Wingate $M$, Alexander $G$. The healthy migrant theory: variations in pregnancy outcomes among US-born migrants. Soc Sci Med. 2006;62: 491-498.

3. Stokols D, Shumaker SA, Martinez J. Residential mobility and personal well-being. J Environ Psychol. 1983;3:5-19.

4. Larson A, Bell M, Young AF. Clarifying the relationship between health and residential mobility. Soc Sci Med. 2004;59:2149-2160.

5. Syme L, Hyman M, Enterline P. Cultural mobility and the occurrence of coronary heart disease. J Health Hum Behav. 1965;4:178-189.

6. Deverteuil G, Hinds A, Lix L, Walker J, Robinson R, Roos LL. Mental health and the city: intra-urban mobility among individuals with schizophrenia. Health Place. 2007;13(2):310-323.

7. Potter LB, Kresnow MJ, Powell KE, et al. The influence of geographic mobility on nearly lethal suicide attempts. Suicide Life Threat Behav. 2001;32:42-48.

8. Lix LM, Hinds A, DeVerteuil G, Renee Robinson J, Walker J, Roos LL . Residential mobility and severe mental illness a population-based study. Adm Policy Ment Health. 2006;33:160-171.

9. Brimblecombe N, Dorling D, Shaw M. Mortality and migration in Britain, first results from the British Household Panel Survey. Soc Sci Med. 1999;49:981-988.

10. Brimblecombe N, Dorling D, Shaw M. Migration and geographical inequalities in health in Britain. Soc Sci Med. 2000;50:861-878.

11. International Organisation for Migration (IOM). World Migration 2005: Cost and Benefit of International Migration. Geneva: International Organisation for Migration; 2005.

12. Global Commission on International Migration (GCIM). Migration in an Interconnected World. Geneva: GCIM; 2005 Oct.

13. Long LH, Boertlein C. The Geographic Mobility of Americans in Comparative Perspective. Washington DC: Current Population Reports No 64 US Government Printing Office; 1976.

14. SCB (2009). Statistisk årsbok för Sverige årgång 2009 (Statistical Yearbook for Sweden 2009). Stockholm: Statistiska Centralbyrån; 2009.

15. Korpi M . Regionala Obalanser-ett Demografiskt Perspective. Institutet för framtidsstudier 23; 2003.

16. Bergström-Levander I (2004). Befolkning och utbildning. Ökade regionala skillnader. Välfärd. 2004;4:12-13.

17. Albin B, Hjelm K, Ekberg J, Elmståhl S. Mortality among 742,668 foreign- and native-born Swedes 1970-1999. Eur J Public Health. 2005;5:511-517.

18. Albin B, Hjelm K, Ekberg J, Elmståhl S. Higher mortality and different pattern of causes of death among foreign-born compared to native Swedes 1970-1999. J Immigrant Minority Health. 2006;2:101-113.

19. Altman D. Practical Statistics for Medical Research. London: Chapman and Hall; 1991.

20. Barefoot JC, Grønbaek M, Jensen G, Schnohr P, Prescott E. Social network diversity and risk of ischemic heart disease and total mortality: findings from Copenhagen city heart study. Am J Epidemiol. 2005;10:960-967. 
21. García EL, Banegas JR, Peréz-Regadera AG, Cabrera RH, RodríguezArtalejo F. Social network and health-related quality of life in older adults. Qual Life Res. 2005;2:511-520.

22. Holtgrave D, Crosby R. Is social capital a protective factor against obesity and diabetes? Ann Epidemiol. 2006;5:406-408.

23. Ekberg J. Egenförsörjning eller bidragsförsörjning? Invandrarna, arbetsmarknaden och välfärden. Stockholm: Fritzes; 2004.

24. Magdol L, Bessel D. Social capital, social currency, and portable assets: the impact of residential mobility on exchanges of social support. Personal Relationships. 2003;10:149-169.

25. National Bureau of Statistics. Population and Housing Census 1970 - Part 7. Stockholm: Allmänna förlaget; 1973.
26. SCB. Statistisk årsbok för Sverige årgång 1973 (Statistical Yearbook for Sweden 1973). Stockholm: Statistiska centralbyrån; 1973.

27. Hull D. Migration, adaptation and illness: a review. Soc Sci Med. 1979;13:25-36.

28. Stave C, Törner M. Exploring the organisational preconditions for occupational accidents in food industry: a qualitative approach. Safety Sci. 2007;45:355-337.

\section{Publish your work in this journal}

Clinical Epidemiology is an international, peer-reviewed, open access journal focusing on disease and drug epidemiology, identification of risk factors and screening procedures to develop optimal preventative initiatives and programs. Specific topics include: diagnosis, prognosis, treatment, screening, prevention, risk factor modification, systematic

Submit your manuscript here: http://www.dovepress.com/clinical-epidemiology-journal

\section{Dovepress}

reviews, risk \& safety of medical interventions, epidemiology \& biostatical methods, evaluation of guidelines, translational medicine, health policies \& economic evaluations. The manuscript management system is completely online and includes a very quick and fair peer-review system, which is all easy to use. 